\title{
Experimental Investigation of Self-Excited Combustion Instabilities in a LOX/LNG Rocket Combustor
}

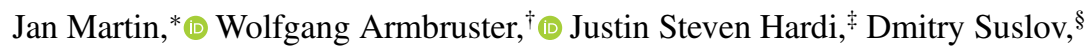 \\ and Michael OschwaldI \\ DLR, German Aerospace Center, 74239 Hardthausen, Germany
}

\begin{abstract}
https://doi.org/10.2514/1.B38289
Two types of combustion instabilities were observed in a multi-injector research combustor with liquid oxygen and liquefied natural gas (LOX/LNG) propellants operating at conditions similar to an upper stage rocket engine. The first was identified as an excited tangential acoustic mode of the combustion chamber and can be explained by coupling with the LOX injectors, similar to the mechanism previously observed in tests with $\mathrm{LOX} / \mathrm{H}_{2}$ propellants. The other type is characterized by longitudinal acoustic oscillations with peak-to-peak amplitudes of at least $40 \%$ of the mean chamber pressure. Analysis of the test data suggests that sudden upstream displacement of a lifted flame may be the trigger mechanism for the second type of instabilities.
\end{abstract}

\section{Nomenclature}

$c=$ sound speed, $\mathrm{m} / \mathrm{s}$

$D \quad=\quad$ chamber diameter, $\mathrm{m}$

$d \quad=\quad$ liquid-oxygen-post diameter, $\mathrm{m}$

$f \quad=$ frequency, $\mathrm{Hz}$

$J \quad=$ momentum flux ratio, $\left(\rho u^{2}\right)_{\mathrm{LNG}} /\left(\rho u^{2}\right)_{\mathrm{LOX}}$

$k_{l}=$ cold zone influence factor for longitudinal modes

$k_{t}=$ cold zone influence factor for transversal and radial modes

$L=$ chamber length from injection plane to nozzle throat

$l_{\text {post,LOX }}=$ liquid-oxygen-post length

$l_{\text {throttle }}=$ length of throttle, $\mathrm{m}$

$M a=$ Mach number

$P \quad=$ static pressure, bar

$p^{\prime} \quad=\quad$ unsteady pressure, bar

$\mathrm{ROF}=$ propellant mixture ratio, $\dot{m}_{\mathrm{LOX}} / \dot{m}_{\mathrm{LNG}}$

$S t \quad=$ Strouhal number

$T=$ temperature, $\mathrm{K}$

$t=$ time, $\mathrm{s}$

$u \quad=$ velocity, $\mathrm{m} / \mathrm{s}$

$\alpha=$ linear growth rate, $1 / \mathrm{s}$

$\eta_{c^{*}} \quad=$ combustion efficiency

$\omega=$ angular frequency, $\mathrm{rad} / \mathrm{s}$

\section{Introduction}

$\mathbf{F}$ UTURE space missions require the development of new rocket engines. The propellant combination of liquid oxygen and methane $\left(\mathrm{LOX} / \mathrm{CH}_{4}\right)$ is predicted to be cheaper and easier to handle

Presented as Paper 2020-0423 at the AIAA SciTech 2020 Forum, Orlando, FL, January 6-10, 2020; received 16 October 2020; revision received 9 April 2021; accepted for publication 29 April 2021; published online Open Access 9 June 2021. Copyright (C) 2021 by the authors. Published by the American Institute of Aeronautics and Astronautics, Inc., with permission. All requests for copying and permission to reprint should be submitted to CCC at www. copyright.com; employ the eISSN 1533-3876 to initiate your request. See also AIAA Rights and Permissions www.aiaa.org/randp.

*Research Engineer, Ph.D. Student, Institute of Space Propulsion; jan.martin@dlr.de.

†Topic Leader Combustion Instabilities, Ph.D. Student, Institute of Space Propulsion; wolfgang.armbruster@dlr.de.

*Head of Rocket Propulsion Technology Department, Institute of Space Propulsion; justin.hardi@dlr.de. Senior Member AIAA.

${ }^{\S}$ Team Leader Thrust Chamber Technology, Institute of Space Propulsion; dmitry.suslov@dlr.de. Senior Member AIAA.

${ }^{\top}$ Coordinator for Rocket Propulsion, Institute of Space Propulsion; also Professorship for Space Propulsion, Institute of Jet Propulsion and Turbomachinery, RWTH Aachen University, 52062 Aachen, Germany; michael. oschwald@dlr.de. Member AIAA. compared with oxygen/hydrogen $\left(\mathrm{LOX} / \mathrm{H}_{2}\right)$. Therefore, the development of methane-fuel technologies in new rocket engines is currently of great interest.

High-frequency combustion instabilities must be avoided during the process of development and operation of any liquid propellant rocket engines (LPREs) [1-3] . Because of the enormous power density in combustion devices for rockets the transfer of a small amount of the total heat release into the acoustic field can cause rapidly growing pressure oscillations to damagingly high amplitudes. Some progress in predicting instabilities has been made in the last decades, although the underlying coupling mechanisms are still not completely understood. Contributions treating $\mathrm{LOX} / \mathrm{CH}_{4}$ systems are rarer than for other propellant combinations because, to date, there have been no $\mathrm{LOX} / \mathrm{CH}_{4}$ engines in operational service. This work reports on combustion instabilities observed in a multi-injector research combustor with LOX/LNG propellants operating at conditions similar to an upper-stage rocket engine. Two types of combustion instabilities with different acoustic characteristics and initiation conditions were identified. Through the analysis of high-frequency pressure measurements it will be shown that the observations are best explained by two different triggering events. The key phenomena in these events are already known to the community as injection coupling and lifted flames.

Injection-coupled mechanisms are characterized by injection flow rate oscillations and acoustic resonance modes of the injector elements affecting the thermoacoustic resonance in the chamber [4]. Injection coupling has been forwarded to explain examples of high-frequency combustion instability with $\mathrm{LOX} / \mathrm{H}_{2}$ since the Apollo program [4-8]. Its occurrence is usually reasoned by the proximity of injector resonance frequencies to combustion chamber acoustic modes. Verification of this hypothesis from the corresponding flame response through optical observations in the combustion chamber is rare $[9,10]$. Examples of coupling with the LOX injector can also be found in some experiments operating with $\mathrm{LOX} / \mathrm{CH}_{4}[\underline{11}, \underline{12}]$.

With slower reaction kinetics and lower flame speeds in LOX $/ \mathrm{CH}_{4}$ combustion compared with $\mathrm{LOX} / \mathrm{H}_{2}[\underline{13}, 14]$ emerges the potential for instabilities relating to flame anchoring. Although stable flame anchoring has consistently been observed for shear coaxial $\mathrm{LOX} / \mathrm{H}_{2}$ injection [15-17], a lifted flame is a possible flame anchoring mechanism with $\overline{\mathrm{LO}} \overline{\mathrm{X}} / \mathrm{CH}_{4}[13]$ and adds another degree of freedom to the complex system of flame-acoustic interaction in rocket combustion chambers.

In this paper, the experimental conditions will first be described under which instabilities were observed. Then, the instabilities will be characterized by the excited eigenmodes of the chamber. Following this the assumed triggers are presented and discussed. 


\section{Experimental Method}

\section{A. Thrust Chamber}

The hot-fire tests analyzed in this work were conducted at the European Research and Technology Test Facility P8 for cryogenic rocket engines with the DLR research thrust chamber model D (BKD). BKD consists of a multi-element injector head, a measurement ring, and a convergent-divergent nozzle. For these tests it was configured with two cylindrical chamber segments each with a length of $200 \mathrm{~mm}$. The combustor configuration is illustrated in Fig. 1a.

The measurement ring is installed between the injector and the chamber segment and is instrumented with four unsteady pressure sensors at the circumferential angular positions of $0,80,180$, and $300^{\circ}$. The signals are sampled at a rate of $100 \mathrm{kHz}$ and have a range of \pm 10 bar. The pressure sensors are mounted to the combustion chamber wall with a recess of $15.75 \mathrm{~mm}$. Two different models from Bergh and Tijdeman [18] and Zhang et al. [19] have been used to analyze the influence on the measurements for this sensor ports. The approaches estimate the resonance frequency of these ports at $18,665 \mathrm{~Hz}$ [18] and at $16,319 \mathrm{~Hz}$ [19]. However, both methods predict a pressure ratio of the measured values below 1.1 and a phase shift of less than $2^{\circ}$ for all frequencies of interest. Because all unsteady pressure sensors are mounted in the same way, the phase shift can be neglected while comparing signal.

The measurement ring also contains 20 thermocouples, protruding $2 \mathrm{~mm}$ into the combustion chamber, in groups of five distributed $90^{\circ}$ apart $\left(T_{\mathrm{HG}}\right)$, and a static pressure sensor $\left(P_{\mathrm{cc}}\right)$, both with a sampling rate of $100 \mathrm{~Hz}$.

LOX and LNG are injected through 42 shear coaxial injection elements with a tapered LOX post, as illustrated in Fig. 1b. The inner diameter of the LOX posts is $d=3.6 \mathrm{~mm}$ and their length is $l_{\text {post } \mathrm{LOX}}=68 \mathrm{~mm}$. The height of the LNG injection gap is $0.25 \mathrm{~mm}$. The LNG was used for cooling of the combustion chamber structure (regenerative cooling) before entering the injector head. Tests were conducted with LOX posts both without recess and with a recess of $2 \mathrm{~mm}$, or $0.54 d$. Because the test runs without recess do not show any instabilities, only tests with recessed configuration are presented here.

\section{B. Operating Conditions}

The tests were conducted with chamber pressures up to 60 bar, ROF up to 2.5 , and a thermal power of up to $60 \mathrm{MW}$. Data from four
Table 1 Overview of test runs

\begin{tabular}{lcccc}
\hline \hline Test ID & A & B & C & D \\
\hline Instability type & 1 & 1 & 2 & 2 \\
Chamber pressure, bar & $50,60,40$ (steps) & \multicolumn{2}{c}{50 (step) } \\
ROF & \multicolumn{1}{c}{$1.5,2$ (steps) } & $1.7-2.7$ (ramped) \\
Constituents (LNG) & \multicolumn{4}{c}{$>99.5 \%$ methane } \\
\hline \hline
\end{tabular}

tests are analyzed in this work, with their instability type summarized in Table 1 . Tests A and B, and C and D, respectively, are repetitions of each other with slight changes in the sequencing. The reader should note that the chamber pressure of some of the load points is very close to the critical pressure of oxygen. However, none of the observations described later show evidence of causal connection to the nearcritical injection regime.

Two of the tests are presented in Fig. 2, with each of the two types of instabilities. The test sequences are described with spectrograms (top) of the unsteady pressure signal (middle), along with traces of the static chamber pressure $P_{\mathrm{cc}}$, LOX injection temperature $T_{\mathrm{LOX}}, \mathrm{LNG}$ injection temperature $T_{\mathrm{LNG}}$, and ratio of oxidizer to fuel mass flow rate ROF (bottom). These traces of parameters describe the performed sequence of operating conditions, whereas the raw unsteady pressure signal (middle) and the spectrogram (top) describe the stability character.

It should be mentioned here that with the same experimental setup two different types of self-excited, high-frequency combustion instabilities were observed for different operating conditions. The transverse combustion instabilities (type 1) occurred at approximately a chamber pressure of 60 bar and ROF of 2 . At the onset of the second type of instabilities, which are characterized by longitudinal pressure oscillations, the pressure in the chamber was roughly 50 bar with an ROF of 1.7.

Tests $\mathrm{C}$ and $\mathrm{D}$ targeted a similar duration to $\mathrm{A}$ and $\mathrm{B}$, but with a sequenced gradual increase in ROF up to $27 \mathrm{~s}$ before stepping to a higher ROF load point. The tests were aborted at $29 \mathrm{~s}$ due to the high amplitude instabilities.

Because of the unexpected nature of the instabilities, the unsteady pressure signals partially exceed their measurement range during phases of high amplitude, which limits the measurement accuracy of amplitude for those cases.

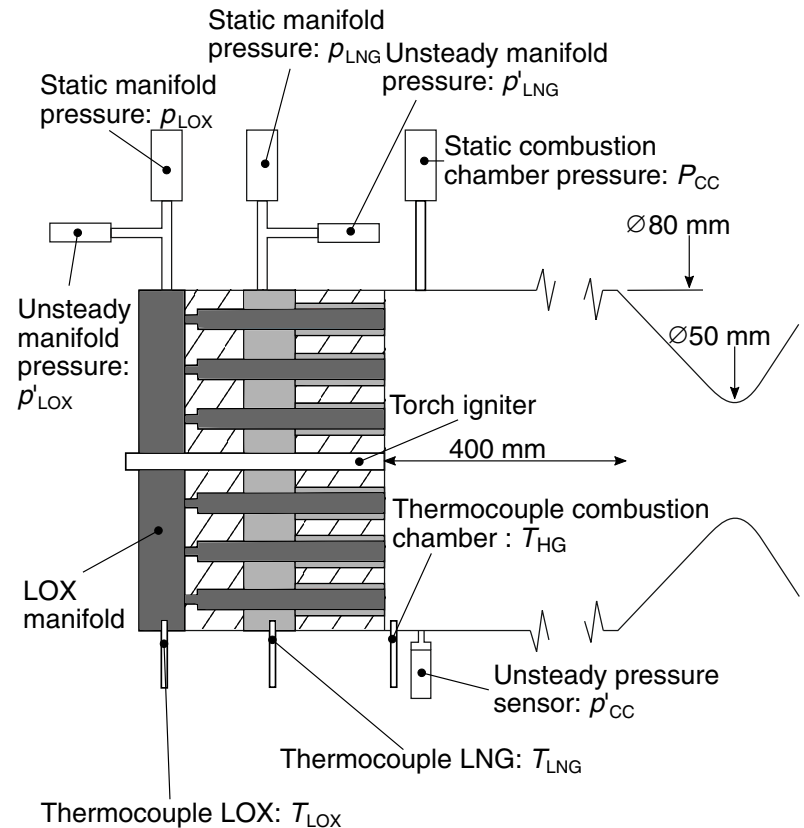

a) Thust chamber schematic

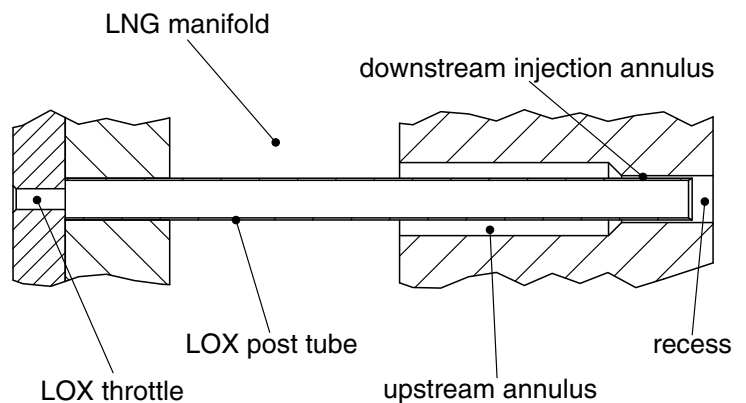

b) Injection element [9]

Fig. 1 Experimental thrust chamber configuration. 


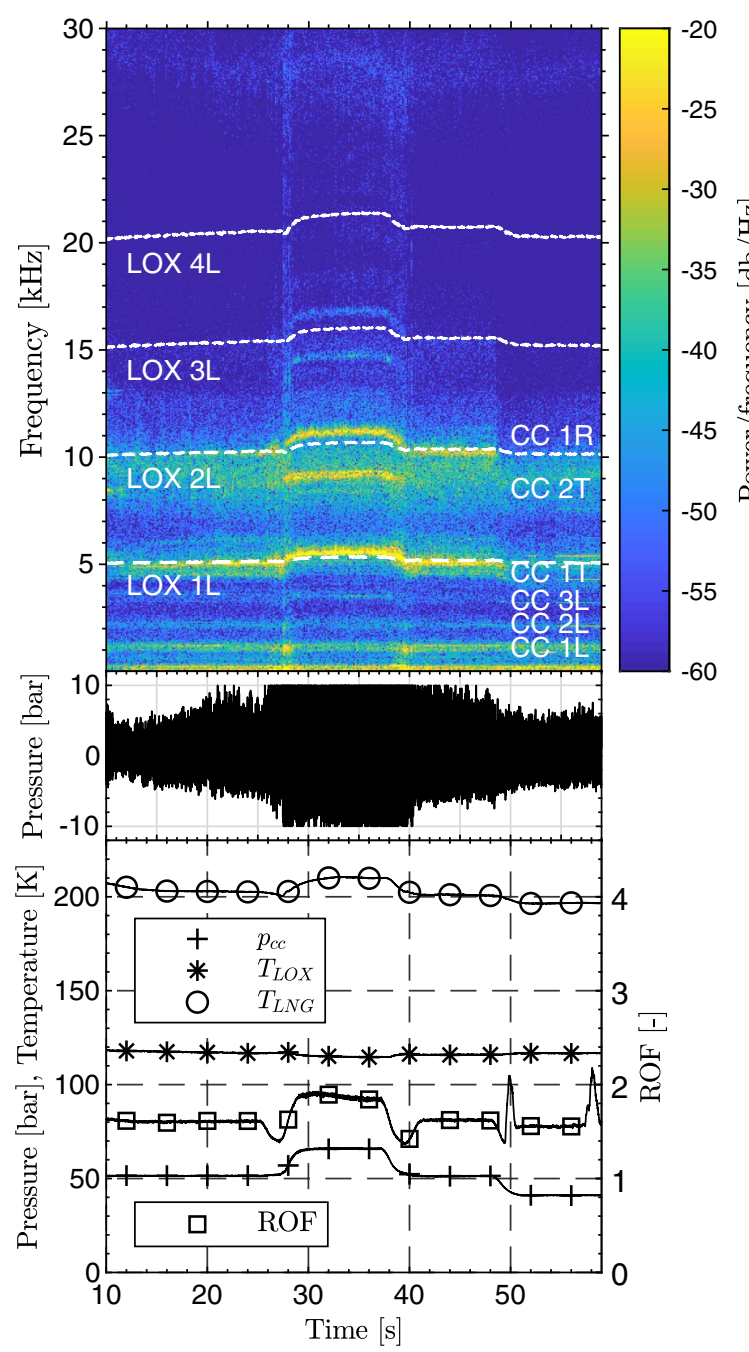

a) Test $A$ with the first type of instabilities

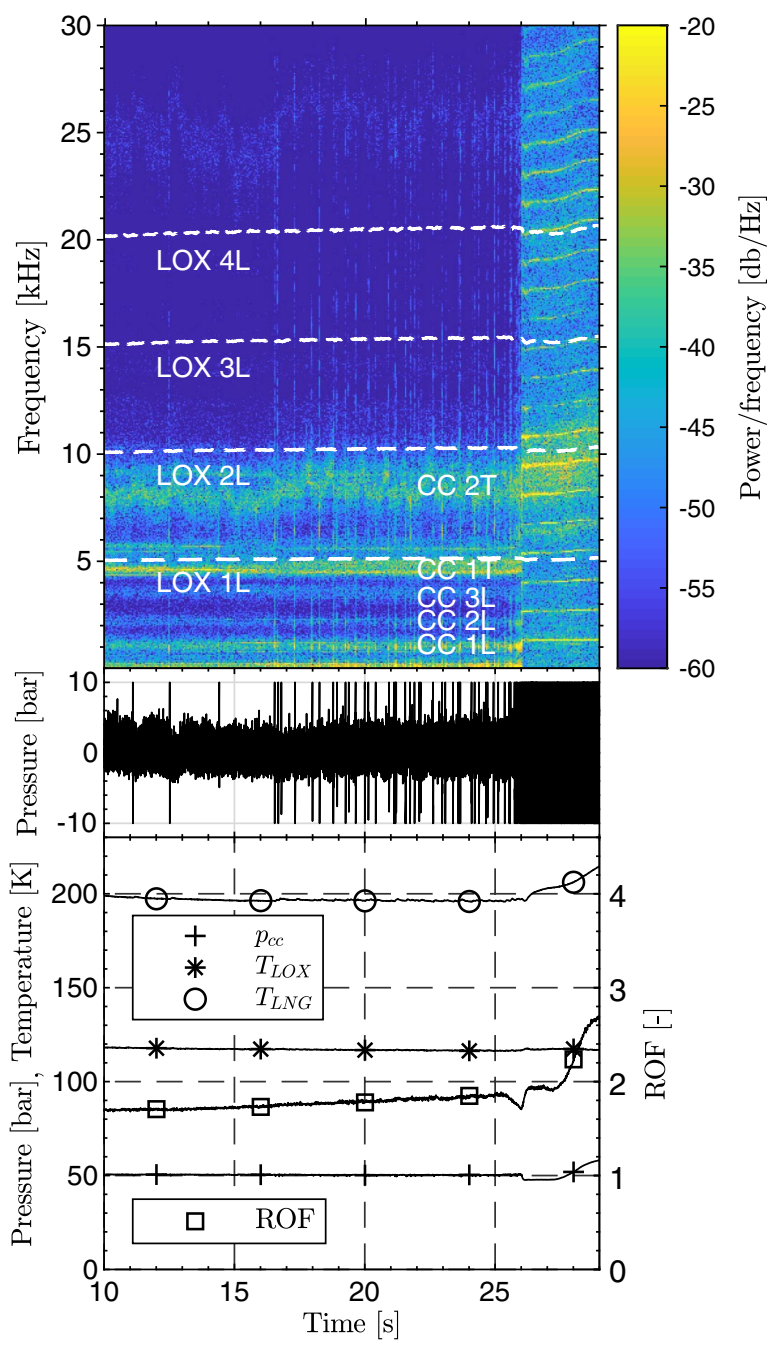

b) Test $\mathrm{C}$ with the second type of instabilities

Fig. 2 Test sequences with operating conditions (bottom), unsteady pressure trace (middle), and spectrogram from unsteady pressure (top).

\section{Acoustic Mode Identification}

A key aspect of the analysis of the unsteady pressure traces presented in this work hinges on the identification of the excited acoustic modes shown in the spectrograms in Fig. 2. Two different approaches were used to identify the spectral peaks belonging to combustion chamber modes.

The first approach considered the phase relationship between the unsteady pressure sensors. First, the pressure signal is band-pass filtered around the frequency range of a distinct mode of interest. Owing to the circumferential distribution of the sensors, it is possible to distinguish tangential modes from longitudinal or radial modes for which all signals oscillate in phase.

The second approach uses Eq. (1) following by Hardi et al. [20] to estimate the frequencies $f$ of different modes:

$$
f=\frac{c\left(\eta_{c *}\right)}{2} \sqrt{\left(\frac{\alpha_{m n}}{D / 2}\right)^{2}\left(1-\bar{M} a^{2}\right) k_{t}^{2}+\left(\frac{q}{L}\right)^{2}\left(1-\bar{M} a^{2}\right)^{2} k_{l}^{2}}
$$

This is a modified version of the analytic equation for linear acoustic eigenmodes in a cylindrical volume, accounting for the axial distribution of the sound speed with correction factors $k_{l}$ for the influence on longitudinal modes and $k_{t}$ for transverse modes. The variable $c\left(\eta_{c^{*}}\right)$ is the equilibrium sound speed in the combustion chamber calculated with NASA CEA with dependence on the combustion efficiency $\eta_{c^{*}}$. Here, $D$ is the diameter; $L$ is the length of the chamber; $m, n$, and $q$ are integer parameters for radial, transverse, and longitudinal modes, respectively; and $\alpha_{m n}$ is the $m$ th root of the radial derivation of the $n$ th-order Bessel function of first kind divided by $\pi$. Finally, a correction for the influence of axial flow through the chamber is performed with the mean Mach number in the combustor $\bar{M} a$.

The estimated frequencies from these methods were consolidated and associated with matching features in the acoustic spectrum, as indicated in the spectrograms in Fig. 2.

LOX-post resonance frequencies are calculated using the formula for an open-open tube with an end correction of $\Delta l=0.8 d$ added to the injector length following Dranovsky [21]:

$$
f_{n L}=\frac{n c_{\mathrm{LOX}}}{2\left(l_{\text {post }, \mathrm{LOX}}+\Delta l\right)}
$$

The modes so identified are also indicated in Fig. 2 as white dashed lines tracing the evolution of mode frequencies with dependence on $c_{\text {LOX }}$.

Having identified the frequencies of combustion chamber modes, the evolution of the distribution of acoustic energy between modes during the unstable periods can be examined. Figure 3 shows the raw unsteady pressure signal, the same signal band-pass filtered from 500 to $1900 \mathrm{~Hz}$ containing the first longitudinal mode (1L) of the chamber, and the signal filtered from 4300 to $5700 \mathrm{~Hz}$ containing the first tangential (1T) mode in all tests. In Fig. 3a it can be seen that the first type of instabilities observed in tests $\mathrm{A}$ and $\mathrm{B}$ has most of its spectral energy in the 1T mode, whereas in Fig. $3 \mathrm{~b}$ the second type in tests $\mathrm{C}$ and $\mathrm{D}$ is seen to be dominated by the $1 \mathrm{~L}$ mode. 


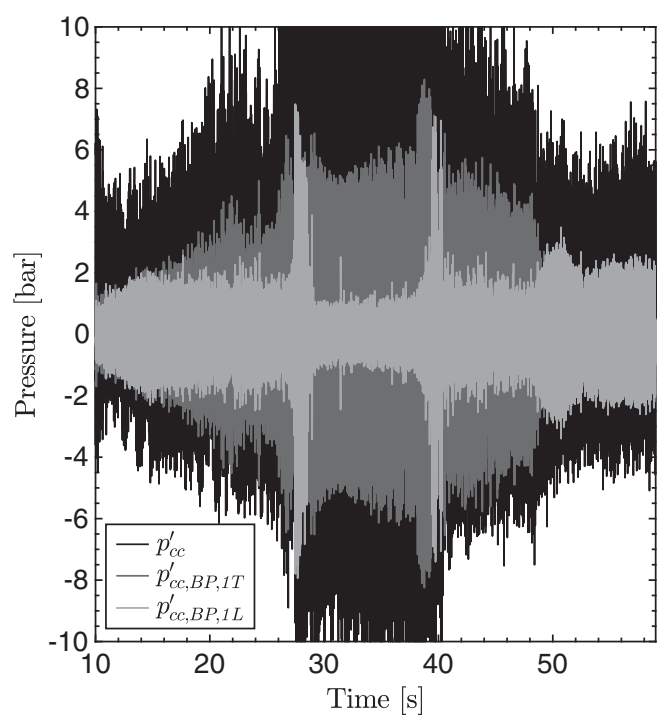

a) Test A: first type of instabilities

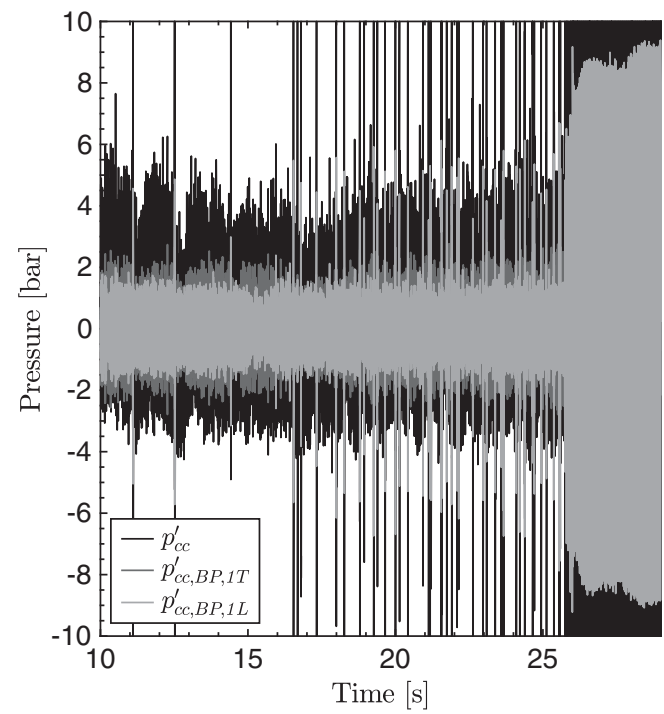

b) Test C: second type of instabilities

Fig. 3 The raw unsteady pressure signal compared with its band-pass-filtered contribution from the 1L mode (500-1900 Hz) and the 1T mode $(4300-5700 \mathrm{~Hz})$.

\section{Results and Discussion}

The characteristics of the two types of instabilities exemplified in tests $\mathrm{A}$ and $\mathrm{C}$ in Fig. 2 will now be examined. The first type of instability, appearing in Fig. 2a between 27.5 and 39 s, is consistent with LOX-post coupled instabilities described by Gröning et al. [8] for the propellant combination $\mathrm{LOX} / \mathrm{H}_{2}$. The second type of instabilities, characterized by pressure spikes followed by heavy instabilities, in Fig. 2b starting at $26 \mathrm{~s}$, does not fit with observations in earlier BKD studies with $\mathrm{LOX} / \mathrm{H}_{2}$ and coaxial injectors. The rise of $T_{\mathrm{LNG}}$ during instability periods can be explained by the increased heat release due to the instabilities and the regenerative cooling setup.

The first type of instability arises when the frequency of one of the LOX-post longitudinal modes coincide with a combustion chamber mode [8]. The frequencies of the first four longitudinal eigenmodes of the LOX post (LOX 1L-4L) are compared with the combustion chamber (CC) eigenmodes in Fig. 2. In both tests the LOX-post 1L and the chamber $1 \mathrm{~T}$ modes around $\overline{5} \mathrm{kHz}$ are in close proximity. But only in test A does the spacing decrease to the point that the 1T mode is heavily excited. Again, it should be noted that signals from both test are affected by clipping of its amplitudes. Even though this introduces the hindrance that an exact measurement of the amplitude is not feasible, there are enough samples in each oscillation to give accurate frequency information.

In test A, clipping mainly occurs at the upper limit of the measurements range. Therefore the spectrogram in Fig. 2a gives a relatively accurate representation of spectral power. Discussion of the spectrogram of test $\mathrm{C}$ will be provided later in this paper. However, the peak instability amplitude in test A is estimated to be between 27.5 and $40 \mathrm{~s}$. Within this interval the amplitude of every pressure cycle exceeds the upper sensor range. At the onset of the high-amplitude instabilities around $28 \mathrm{~s}$ and the end around $39 \mathrm{~s}$ the $1 \mathrm{~L}$ mode blossoms. It is believed that during the transition to the next load point (LP) the combustor passes through operating conditions with reduced damping and increased excitation of the chamber 1L mode.

Although the frequencies drift apart somewhat due to the change in operating condition during the time of peak instability, the 1T mode is most excited at this LP. An explanation is offered by the orifice whistling phenomenon reported in BKD by Armbruster et al. [9]. They found that hydrodynamic excitation of LOX-post longitudinal modes is greatest for Strouhal numbers of the flow through the throttle section $\left(S t_{\text {throttle }}=\left(f_{\text {whistling }} \cdot l_{\text {throttle }}\right) / u_{\text {throttle }}\right)$ approaching 0.35 .

This relationship was checked for the current LOX/LNG tests, and Fig. 4 shows the temporal evolution of $S t_{\text {throttle }}$ for all four test runs. It can be seen that for tests A and B (Fig. 4a) the strong instability begins when $S t_{\text {throttle }}$ decreases to 0.4 with the change in $p_{\text {cc }}$, although the frequency difference between the post $1 \mathrm{~L}$ and CC $1 \mathrm{~T}$ modes was slightly larger. On the other hand, the start of the instability interval

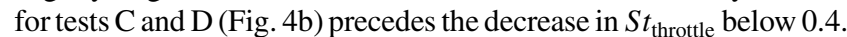

In fact, the spectrogram of test $\mathrm{C}$ in Fig. $2 \mathrm{~b}$ does not indicate any particular coupling of chamber and injector modes. At first sight this spectrogram appears to show that the dominant frequency of the instability from 26 to $29 \mathrm{~s}$ is in the range 9 to $10 \mathrm{kHz}$. However, examining the band-pass-filtered root mean square (RMS) values of the 3 signals in this interval indicates that this impression is an artifact of the spectrogram appearance. The RMS values are 5.7 bar for the $1 \mathrm{~L}$ mode and 2.6 bar for the $9-10 \mathrm{kHz}$ range. This latter value is roughly the same as for the $2 \mathrm{~L}$ mode with 2.1 bar. Furthermore, it should be noted that the overtones are exaggerated by the clipping of the high-amplitude signal when it exceeds the preset measurement range of the sensor.

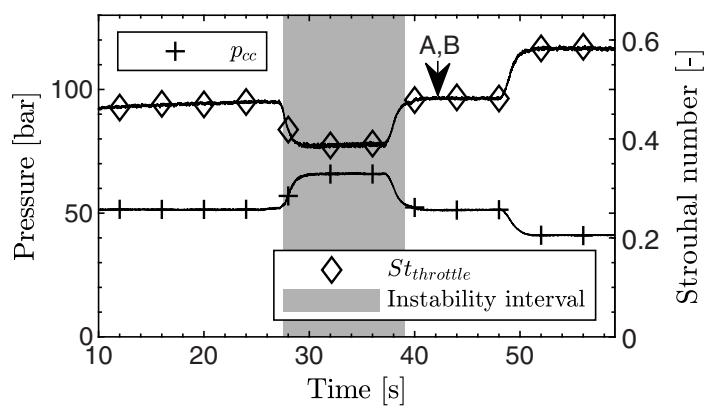

a) Tests $A$ and $B$

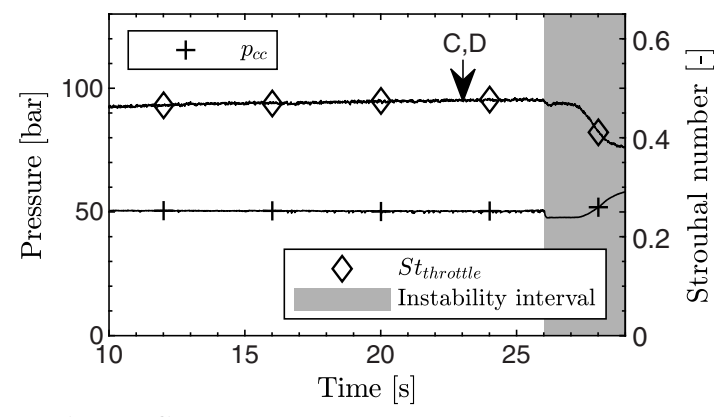

b) Tests $\mathbf{C}$ and $\mathrm{D}$

Fig. 4 Chamber pressure and LOX throttle Strouhal number for the 1L frequency of the LOX post. 


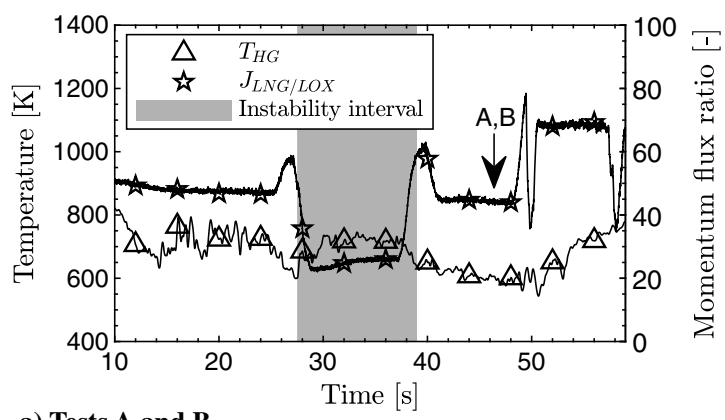

a) Tests $A$ and $B$

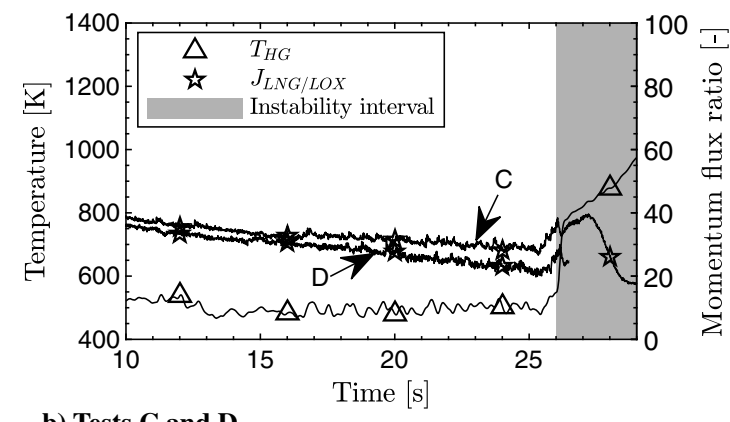

b) Tests $\mathbf{C}$ and $\mathrm{D}$

Fig. 5 Combustion chamber gas-side temperature at the measurement ring, and momentum flux ratio at the injection element.

Nevertheless, neither of the two aforementioned mechanisms can explain the instabilities in test $\mathrm{C}$. The frequency spacing between the chamber and post modes is greater than in test A and the $S t_{\text {throttle }}$ is relatively high in the vicinity of 0.45 , at the onset of instabilities. Because the $1 \mathrm{~L}$ mode of the LOX post is nearly identical in both runs, the main cause for the greater spacing to the chamber 1T mode appears to be a lower speed of sound in the chamber. With nearidentical injection conditions, a lower speed of sound implies lower temperatures in the upstream part of the chamber.

Considering the measurements from temperature probes located in the measurement ring presented in Fig. 5, a drastically reduced value in the vicinity of the face plate, around $200 \mathrm{~K}$ lower, is found in tests $\mathrm{C}$ and D (Fig. 5b) compared with tests A and B (Fig. 5a). Given that the injection temperatures of the propellants and the ROF vary little between test runs, the heat release distribution from the combustion field in the chamber is likely to be responsible. In other words, it seems reasonable to assume that a lifted flame could be the cause of these observations. Figure $\underline{6}$ further supports this supposition. It can be observed that the load points hypothesized to have a lifted flame also have a lower pressure drop for the fuel injection, whereas the LOX pressure drop is unaffected. Kendrick et al. [22] showed that a recessed injector leads to acceleration of the annular fuel flow as it is pinched by the flame expanding inside the recess region, and thus results in an increased pressure drop. Conversely, a reduced pressure drop, at least for the fuel injection, could indicate a lifted flame.

The cause of a presumably lifted flame in tests C and D is unknown. The main difference between the two sets of tests in terms of injection parameters is the momentum flux ratio ( $J$ number) of the injected propellants. In general, $J$ is believed to represent the forces that govern the primary breakup of the LOX jet in shear coaxial injectors [23-25]. Higher values of $J$ indicate enhanced the mixing processes between oxidizer and fuel [26].

Figure 5 shows that $J$ is lower for nearly all phases of tests $C$ and $D$ than in $\mathrm{A}$ and $\mathrm{B}$. It is therefore hypothesized that poorer jet breakup and mixing favor detachment of the flame from the LOX-post tip and anchoring in the shear layer further downstream. An exception to the lower $J$ value condition is during the unstable interval in tests A and B. In this case it is supposed that the possible degradation in anchoring from a low $J$ is counteracted by the strong transverse velocity

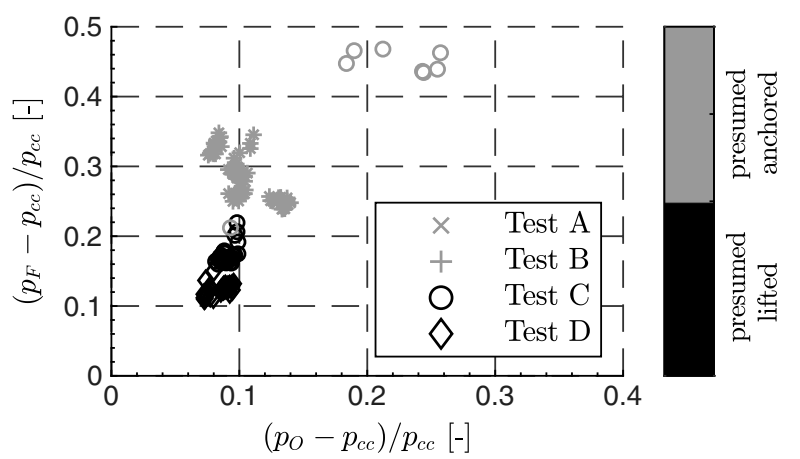

Fig. 6 Pressure drop between dome volumes and combustion chamber for tests A-D with respect to the assumed flame anchoring mechanism. perturbations near the faceplate of the $1 \mathrm{~T}$ mode enhancing the primary jet breakup and mixing process.

For the rest of tests $\mathrm{C}$ and $\mathrm{D}, J$ is continuously decreasing, yet the mean temperature at the measurement ring remains approximately constant. This is consistent with the experimental results of Yang et al. [13], who found no dependency of the liftoff distance of $\mathrm{LOX} / \overline{\mathrm{CH}}_{4}$ flames on $J$.

To support the lifted flame assumption for tests $\mathrm{C}$ and $\mathrm{D}$, the factors $k_{l}$ and $k_{t}$ in Eq. (1) were recalculated taking into account the extended "cold zone" at the head end of the chamber due to the lifted flame. A liftoff distance of $30 \mathrm{~mm}$ reduces the factor $k_{l}$ by 0.04 and $k_{t}$ by 0.1 , and the resulting mode frequencies matched the measured frequencies well. Table 2 shows the experimental frequency in comparison with the calculated frequencies based on the analytic equation for linear acoustic eigenmodes without any correction, with correction for the axial distribution of the sound speed, and additionally accounting for a lifted flame. Therefore, the distribution of measured mode frequencies for transverse and longitudinal modes supports the hypothesis of a lifted flame.

In later test runs, the injector was exchanged for a version without recessed LOX posts. In all tests with the nonrecessed configuration, neither instabilities nor evidence of a lifted flame was observed. This leads to the presumption that the LOX-post recess influenced the flame anchoring behavior in an unfavorable way. The aforementioned pinching effect of the recess region on the fuel injection flow can also be applied for explaining this observation. Higher relative injection velocities might exceed the flame propagation speed and cause it to blow off. But an acceleration of the fuel injection velocity also leads to an increase in $J$. This contradicts the hypothesis that a lifted flame in tests $\mathrm{C}$ and $\mathrm{D}$ is due to the lower $J$ values, unless flame anchoring in this combustor configuration is a bistable system with particular ranges of stable $J$ values. The absence of the first type of instabilities in the later test runs without recessed LOX post might be explained by their nature as LOX-post coupled instabilities. Hulka and Hutt [5] hypothesized that the recessed area acts as a precombustor and amplifies LOX-post acoustic. This potential amplification source and therefore influence on chamber acoustics are lacking in the later tests without recess. Furthermore, conventional wisdom on the design of shear coaxial injectors for $\mathrm{LOX} / \mathrm{H}_{2}$ says that recess has a stabilizing influence against combustion instabilities, although this may be limited to the transverse modes [1]; hence the flame in the LOX-post recess is protected from transverse acoustic waves. The protective effect might not apply for longitudinal acoustic waves, which may enter the recessed area more easily even though there will

Table 2 Comparison of experimental and estimated frequencies

\begin{tabular}{|c|c|c|c|c|}
\hline $\begin{array}{l}\text { Test, interval, } \\
\text { mode }\end{array}$ & $\begin{array}{l}\text { Experimental } \\
\text { frequency }\end{array}$ & $\begin{array}{l}\text { Analytic } \\
\text { frequency }\end{array}$ & $\begin{array}{c}\text { Analytic } \\
\text { frequency incl. } \\
\text { correction for } \\
\text { sound profile } \\
\end{array}$ & $\begin{array}{c}\text { Analytic } \\
\text { frequency incl. } \\
\text { correction for } \\
\text { sound profile and } \\
\text { lifted flame } \\
\end{array}$ \\
\hline $\begin{array}{l}\text { Test C, } \\
10-26 \mathrm{~s}, 1 \mathrm{~T}\end{array}$ & $4700 \mathrm{~Hz}$ & $8742 \mathrm{~Hz}$ & $5164 \mathrm{~Hz}$ & $4740 \mathrm{~Hz}$ \\
\hline
\end{tabular}


be a gradient in the acoustic impedance. Further investigation is required to consolidate these observations.

Another feature of tests $\mathrm{C}$ and $\mathrm{D}$ are intermittent pressure spikes. Starting at $11 \mathrm{~s}$ in Fig. $2 \mathrm{~b}$, the unsteady pressure sensor shows pressure spikes exceeding the sensor measurement range. After the occurrence of a pressure spike a rise in temperature is registered. The temporal correlation of temperature probes in the measurement ring and the pressure spikes, indicated by a high RMS value, is illustrated in Fig. 7. Considering an experienced based reaction time of the thermocouples of $200 \mathrm{~ms}$, it can be seen that every pressure spike

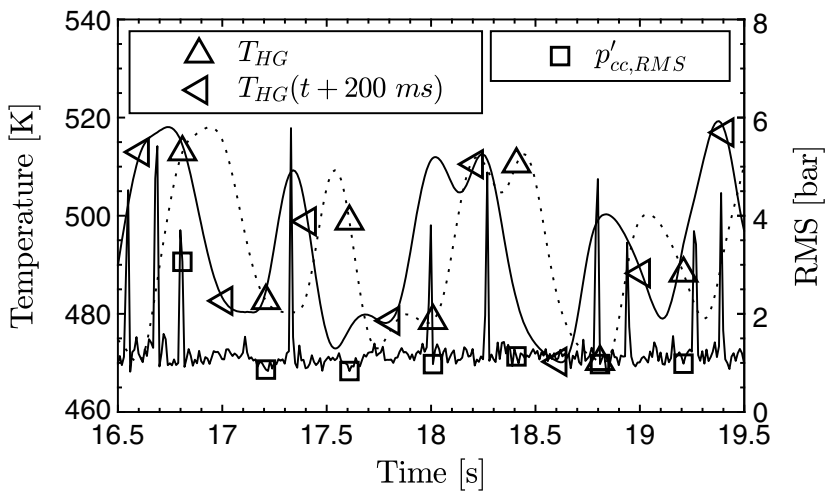

Fig. 7 Temperature and RMS of unsteady pressure in measurement ring.

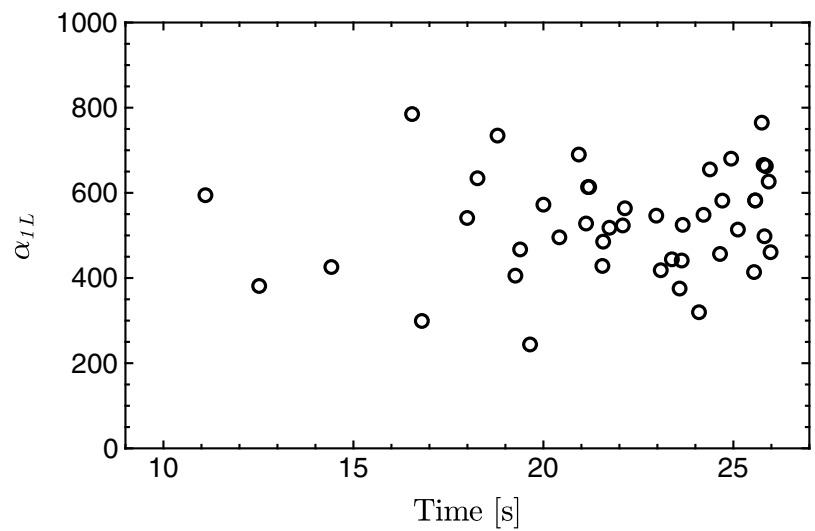

Fig. 8 Unsteady pressure signals from test $\mathrm{C}$ with the second type of instabilities in Fig. 3b.

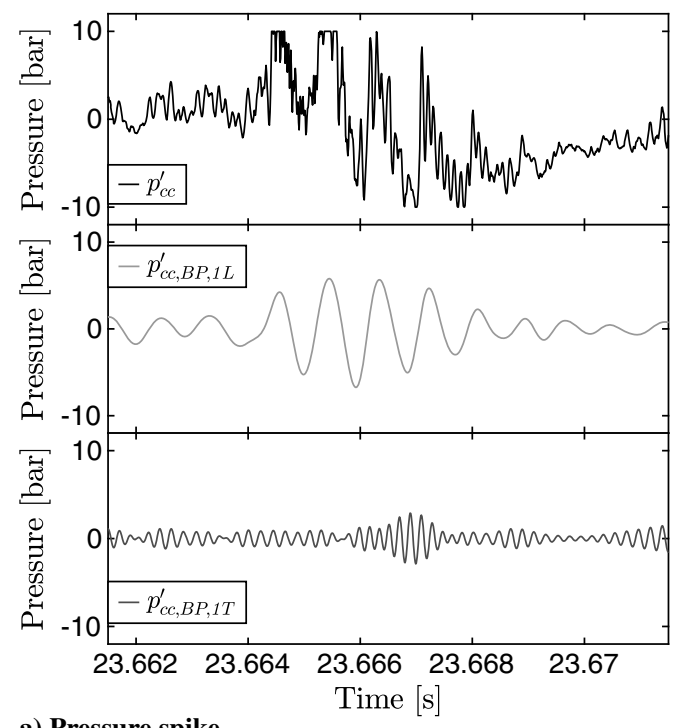

matches an increase in temperature. This behavior is therefore presumed to result from sudden upstream translation of the combustion zone toward the injection plane. The overpressure in the head end of the chamber is certain to interrupt the injected flow of propellants, precluding a stable re-anchoring of the flame at the injector exit.

During the test shown in Fig. 2b, the pressure spikes are seen to occur with increasing frequency. From $12.5 \mathrm{~s}$ the ROF increases due to the drop of the fuel mass flow rate, and consequently $J$ decreases, as seen in Fig. 5b. It is currently unclear how these parameters influence the occurrence of the pressure spikes.

Each pressure spike event, like that in Fig. 8a, is seen to excite the $1 \mathrm{~L}$ mode, which dampens out after a few cycles. The damping of these pressure spikes can be characterized according to the equation for a driven and damped harmonic oscillator:

$$
p^{\prime}(t)=p^{\prime}(0) \exp ^{i \omega t} \exp ^{-\alpha t}
$$

Here, $\alpha$ denotes the linear growth rate, which is the difference between growth and damping rates [27]. A negative value indicates growth of the amplitude, and a positive value damping of the oscillations [28]. If for a pressure spike event, Eq. (3) is fitted with the method of least squares to the band-pass-filtered unsteady pressure signal of the chamber 1L mode (e.g., $p_{\text {cc,BP, } 1 L}^{\prime}$ in Fig. $\underline{\text { aa) }}$ the damping rate can be determined. Figure 9 shows the damping characteristics of the pressure spikes between $1 \overline{0}$ and $25.9 \mathrm{~s}$. The damping rate seems not to change over the course of time, although ROF (1.7-1.9) and J (40-20) are changing. Within this interval no dependency of the combustor damping characteristics with respect to injection parameters was found.

Finally, at around $25.9 \mathrm{~s}$ in test $\mathrm{C}$, one of the pressure spikes triggers sustained, high-amplitude instabilities of the chamber $1 \mathrm{~L}$ mode. Figure 8 gives a zoomed view of the raw and band-pass pressure signals of Fig. $3 \mathrm{~b}$ from test $\mathrm{C}$, for one of the earlier pressure spikes (Fig. 8a), and the onset of instabilities (Fig. 8b). For this type of instabilities' operating conditions, reducing the damping of longitudinal modes seems to be quite important. The combination of a chamber environment allowing an excitation of longitudinal pressure perturbations and the presumed sudden upstream movement of the flame inducing a pressure spike is hypothesized to be the key interaction for the onset and persistence of the second type of instabilities. Between 10 and 26 s mainly the ROF and the momentum flux ratio are changed by decreasing the fuel mass flow rate while the oxygen mass flow is kept constant. The chamber pressure and the damping characteristics show negligible reactions to these changed injection conditions. Perhaps due to the additional change of the chamber pressure during transition to the next aimed LP at approximately $26 \mathrm{~s}$, the damping characteristics are changed more

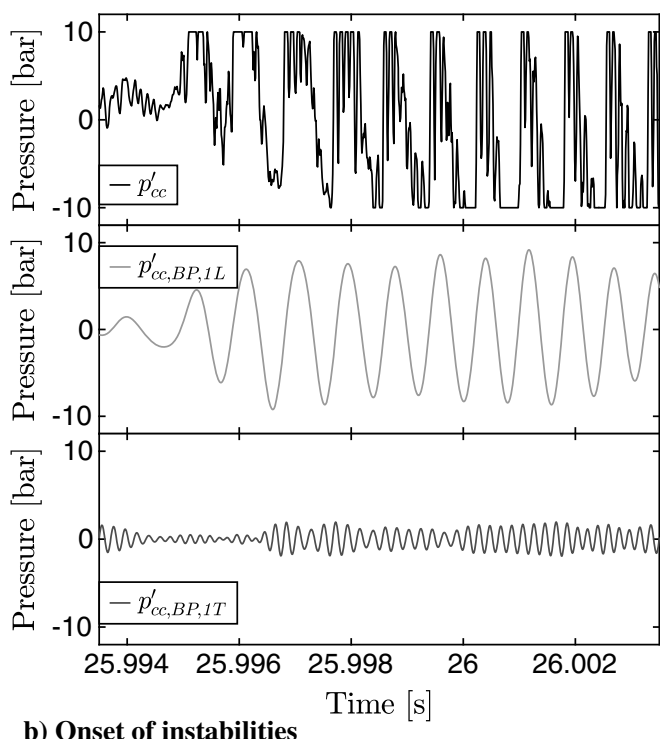

Fig. 9 Damping rate of the band-pass-filtered pressure perturbations with respect to the chamber $1 \mathrm{~L}$ mode in test $\mathrm{C}$ between 10 and $26 \mathrm{~s}$. 
significantly and the system is no longer capable of damping the perturbation induced by the flame flashing back and it is pushed into a limit cycle instability. During the instability, the head-end gas temperatures and the resonance frequencies increase, suggesting a sustained upstream shift in the mean combustion distribution. It should be noted that the operating conditions during the transition phases at 28, 39, and $49 \mathrm{~s}$ in test A also lead to a short period of increased 1L mode amplitudes. Those operating conditions are all characterized by an ROF of 1.4 and chamber pressures in the vicinity of 50 bar. The measured data suggest a different ROF at similar pressure conditions in test $\mathrm{C}$ at the onset of high-amplitude longitudinal instabilities. All cases of a blossoming $1 \mathrm{~L}$ mode in test $A$ and the instabilities in test $C$ have a steep increase of the fuel mass flow rate and thus a dropping ROF preceding their occurrence in common. Possibly this leads, at least temporarily, to a greater share of gaseous media in the cross-sectional area of the recess and therefore to a changed gradient of the acoustic impedance at the interface between recessed volume and chamber, supporting interaction of longitudinal acoustic waves and injection. However, a final explanation cannot be given with the data from these experiments. To tackle this topic in full extent, additional testing with optical access investigating the response of the flame during the transition phases between two load points, accompanied by appropriate modeling, would be necessary.

\section{Conclusions}

Two different types of instabilities occurring in a subscale LOX/LNG rocket thrust chamber were analyzed in this work. While the driving mechanism for the first type could be traced back to a LOX-post coupled instability, the source for the second type is uncertain, and is proposed in this paper to be due to changes in flame anchoring behavior.

For the first instability it was observed that the amplitude of the pressure fluctuations in the chamber increased when the frequency spacing between the first tangential acoustic mode of the combustion chamber and the first longitudinal resonance mode of the LOX post was small. When additionally the Strouhal number of the periodic vortex shedding at the LOX throttle element approaches a value of 0.35 the amplitude increased further.

The second type of instability was hypothesized to be triggered by the sudden upstream flash-back of a primarily lifted flame. In this case, the sustained, high-amplitude instability of the first longitudinal mode of the combustion chamber was preceded by a long period of stable combustion but with characteristics suggesting a lifted flame. These characteristics were primarily lower hot gas temperatures in the chamber and lower acoustic mode frequencies. This period was also marked by intermittent, short-lived, flame translation events, which were accompanied by high-amplitude, steep-fronted peaks in unsteady pressure; sudden increases in hot gas temperature at the head end of the chamber; and sudden increases in acoustic mode frequencies. The sustained instability was initiated by one such event.

Based on the difference in injection conditions between stable and unstable tests, it appears that in the absence of combustion instabilities a lower value of momentum flux ratio leads to a detached flame. The evidence for a lifted flame followed by re-anchoring at the LOX-post tip is based on temperature and unsteady pressure measurements. Certainty could be provided by optical measurements, but these were not available in the tested configuration. Future experiments are planned with optical access to the injection plane to give more insight into the flame anchoring processes with LOX/LNG.

One important aspect of the current observations is that the injector without LOX-post recess was stable, whereas both types of instability occurred with the recessed injector. This is in contradiction with conventional wisdom on the design of shear coaxial injectors for $\mathrm{LOX} / \mathrm{H}_{2}$ in which recess has a stabilizing influence on transverse combustion instabilities. Further investigations regarding this aspect should be addressed.

\section{Acknowledgments}

This work is associated with the Franco-German Rocket Engine Stability iniTiative (REST). The authors would also like to thank the crew of the P8 test bench. Thanks also to Jan Haemisch for providing the experimental data and Alex Grebe for his assistance in performing the experiments.

\section{References}

[1] Harrje, D., and Reardon, F. (eds.), "Liquid Propellant Rocket Combustion Instability," NASA SP-194, 1972.

[2] Sutton, G. P., and Biblarz, O., Rocket Propulsion Elements, 8th ed., Wiley, New York, 2010, Chap. 9.3.

[3] Anderson, W. E., and Yang, V. (eds.), Liquid Rocket Engine Combustion Instability, AIAA, Washington, D.C., 1995, Chap. 1. https://doi.org/10.2514/4.866371

[4] Hutt, J. J., and Rocker, M., "Fundamental Mechanisms of Combustion Instabilities: High-Frequency Injection-Coupled Combustion Instability," Liquid Rocket Engine Combustion Instability, edited by V. Yang, and W. E. Anderson, AIAA, Washington, D.C., 1995, pp. 345-355, Chap. 12. https://doi.org/10.2514/5.9781600866371.0345.0355

[5] Hulka, J., and Hutt, J. J., "Instability Phenomenology and Case Studies: Instability Phenomena in Liquid Oxygen/Hydrogen Propellant Rocket Engines," Liquid Rocket Engine Combustion Instability, edited by V. Yang, and W. E. Anderson, AIAA, Washington, D.C., 1995, pp. 39-71, Chap. 2.

https://doi.org/10.2514/5.9781600866371.0039.0071

[6] Wanhainen, J. P., Parish, H. C., and Conrad, E. W., "Effect of Propellant Injection Velocity on Screech in 20000-Pound Hydrogen-Oxygen Rocket Engine," NASA TN D-3373, 1966.

[7] Wanhainen, J. P., Feiler, C. E., and Morgan, C. J., "Effect of Chamber Pressure, Flow per Element, and Contraction Ratio on Acoustic-Mode Instability in Hydrogen-Oxygen Rockets," NASA TN D-4733, 1968.

[8] Gröning, S., Hardi, J. S., Suslov, D., and Oschwald, M., "InjectorDriven Combustion Instabilities in a Hydrogen/Oxygen Rocket Combustor,' Journal of Propulsion and Power, Vol. 32, No. 3, 2016, pp. 560-573.

https://doi.org/10.2514/1.B35768

[9] Armbruster, W., Hardi, J. S., Suslov, D., and Oschwald, M., "InjectorDriven Flame Dynamics in a High-Pressure Multi-Element OxygenHydrogen Rocket Thrust Chamber," Journal of Propulsion and Power, Vol. 35, No. 3, 2019, pp. 632-644. https://doi.org/10.2514/1.B37406

[10] Oschwald, M., and Knapp, B., "Investigation of Combustion Chamber Acoustics and Its Interaction with LOX/H2 Spray Flames," Progress in Propulsion Physics, Vol. 1, No. 1, 2009, pp. 205-224. https://doi.org/10.1051/eucass/200901205

[11] Kawashima, H., Kobayashi, K., and Tomita, T., "A Combustion Instability Phenomenon on a LOX/Methane Subscale Combustor," 46th AIAA/ASME/SAE/ASEE Joint Propulsion Conference \& Exhibit 2010, AIAA Paper 2010-7082, 2010. https://doi.org/10.2514/6.2010-7082

[12] Jensen, R. J., Dodson, H. C., and Claflin, S. E., "LOX/Hydrocarbon Combustion Intability Investigation," Rockwell International Corp., NASA CR 182249, Canoga Park, CA, July 1989.

[13] Yang, B., Cuoco, F., and Oschwald, M., "Atomization and Flames in LOX/H2- and LOx/CH4-Spray Combustion," Journal of Propulsion and Power, Vol. 23, No. 4, 2007, pp. 763-771. https://doi.org/10.2514/1.26538

[14] Fiock, E. F., "Physical Measurements in Gas Dynamics and Combustion," High Speed Aerodynamics and Jet Propulsion, Vol. 9, Princeton Univ. Press, Princeton, NJ, 1954, pp. 409-438.

[15] Mayer, W., and Smith, J., "Fundamentals of Supercritical Mixing and Combustion of Cryogenic Propellants," Liquid Rocket Thrust Chambers, AIAA, Reston, VA, 2004, pp. 339-367. https://doi.org/10.2514/5.9781600866760.0339.0367

[16] Herding, G., Snyder, R., Scouflaire, P., Rolon, C., and Candel, S., "Flame Stabilization in Cryogenic Propellant Combustion," Symposium (International) on Combustion, Vol. 26, No. 2, 1996, pp. 2041-2047. https://doi.org/10.1016/S0082-0784(96)80028-2

[17] Candel, S., Herding, G., Synder, R., Scouflaire, P., Rolon, C., Vingert, L., Habiballah, M., Grisch, F., Péalat, M., Bouchardy, P., Stepowski, D., Cessou, A., and Colin, P., "Experimental Investigation of Shear Coaxial Cryogenic Jet Flames," Journal of Propulsion and Power, Vol. 14, No. 5, 1998, pp. 826-834. https://doi.org/10.2514/2.5346 
[18] Bergh, H., and Tijdeman, H., "Theoretical and Experimental Results for the Dynamic Response of Pressure Measuring Systems by H. Bergh and H. Tijdeman," National Aero- and Astronautical Research Inst. NLRTRF.238, Amsterdam, Jan. 1965. https://doi.org/10.13140/2.1.4790.1123

[19] Zhang, M., Thompson, W., Frendi, A., and Casiano, M. J., "Acoustic Wave Propagation in a Sensor Port: Experimental Measurements and Analytical Model Predictions," Applied Acoustics, Vol. 127, Dec. 2017, pp. 1-14.

https://doi.org/10.1016/j.apacoust.2017.05.008

[20] Hardi, J., Deeken, J., Armbruster, W., Miene, Y., Haemisch, J., Martin, J., Suslov, D., and Oschwald, M., "LUMEN Thrust Chamber-Injector Design and Stability Analysis," 32th International Symposium on Space Technology and Science (ISTS), Japan Soc. for Aeronautical and Space Sciences (JSASS), Paper 2019-a-10, 2019.

[21] Dranovsky, M. L., Combustion Instabilities in Liquid Rocket Engines, AIAA, Reston, VA, 2007, pp. 1-307. https://doi.org/10.2514/4.866906

[22] Kendrick, D., Herding, G., Scouflaire, P., Rolon, C., and Candel, S., "Effects of a Recess on Cryogenic Flame Stabilization," Combustion and Flame, Vol. 118, No. 3, 1999, pp. 327-339. https://doi.org/10.1016/S0010-2180(98)00168-0

[23] Lasheras, J. C., Villermaux, E., and Hopfinger, E. J., "Break-Up and Atomization of a Round Water Jet by a High-Speed Annular Air Jet," Journal of Fluid Mechanics, Vol. 357, Feb. 1998, pp. 351-379. https://doi.org/10.1017/S0022112097008070
[24] Davis, D. W., and Chehroudi, B., "Measurements in an Acoustically Driven Coaxial Jet Under Sub-, Near-, and Supercritical Conditions," Journal of Propulsion and Power, Vol. 23, No. 2, 2007, pp. 364-374. https://doi.org/10.2514/1.19340.

[25] Woodward, R., Pal, S., Farhangi, S., and Santoro, R., "LOX/GH2 Shear Coaxial Injector Atomization Studies at Large Momentum Flux Ratios," 42nd AIAA/ASME/SAE/ASEE Joint Propulsion Conference \& Exhibit, AIAA Paper 2006-5203, 2006. https://doi.org/10.2514/6.2006-5203

[26] Tani, H., Teramoto, S., and Okamoto, K., "Effects of Injector Geometry on Cryogenic Shear Coaxial Jets at Supercritical Pressures," Journal of Propulsion and Power, Vol. 31, No. 3, 2015, pp. 883-888. https://doi.org/10.2514/1.B35530

[27] Noiray, N., "Linear Growth Rate Estimation from Dynamics and Statistics of Acoustic Signal Envelope in Turbulent Combustors," Journal of Engineering for Gas Turbines and Power, Vol. 139, No. 4, 2016, Paper 041503. https://doi.org/10.1115/1.4034601

[28] Webster, S., "Analysis of Pressure Dynamics, Forced Excitation and Damping in a High Pressure LOX/H2 Combustor," Ph.D. Thesis, RWTH Aachen, Aachen, Germany, 2016.

A. K. Gupta Associate Editor 